\title{
The role of embodied cognition in sports officiating
}

\author{
Alexandra Pizzera \\ German Sport University, Cologne, Germany
}

Received 27 November 2013 - Accepted 18 November 2014

\begin{abstract}
Sports officials are responsible for the correct enforcement of laws and regulations at sporting competitions and games. To meet these high expectations and making correct judgments and the right decisions, they have to develop a great amount of expertise, usually reached through a variety of experiences and different sources of information. For instance, one of the factors influencing the performance of sports officials and therefore leading to expertise comes from the sports officials themselves, by developing alongside their sporting career. The following chapter will give an overview of a new perspective on expertise of sports officials by focusing on these internal factors from an embodied cognition viewpoint. In more detail, studies will be reviewed that have analyzed and interpreted the sports officials' previous experiences as athletes (motor experience) and spectators (visual experience) and their officiating experiences in terms of their relation to officiating performance. This line of research in embodied officiating addresses the link between cognitive judgments of sports officials and their motor, visual and officiating experiences. Recent research will be described and transferred to the applied field of sports officials, offering practical implications based on scientific findings. This review will show that in order to describe and understand expertise in sports officiating from a holistic point of view, the field of embodied cognition should be integrated, which so far has been neglected in sports officiating research.
\end{abstract}

Key words: Judges, referees, embodied cognition, expertise

Résumé. Le rôle da la cognition incarnée dans l'arbitrage des pratiques sportives.

Les arbitres des pratiques sportives ont la responsabilité de l'application des lois et des règles lors des rencontres sportives. Pour répondre à de telles attentes, effectuer des jugements corrects et prendre des décisions appropriées, ils doivent développer une expertise la plupart du temps atteinte par des expériences variées et de nombreuses sources d'information. Par exemple, l'un des facteurs influençant la performance des officiels des pratiques sportives et par conséquent permettant d'atteindre un haut niveau d'expertise provient des officiels eux-mêmes tout au long de leur carrière sportive. Cet article aborde une perspective de l'expertise des officiels des pratiques sportives en se focalisant sur ces facteurs internes à partir du point de vue de la cognition incarnée. Plus spécifiquement, les études qui ont analysé et interprété les expériences antérieures des officiels en tant qu'athlète (expérience motrice) et leurs expériences en tant qu'arbitre sont revues et discutées dans leur relation avec la performance arbitrale. Cette orientation de la recherche sur l'arbitrage incarnée aborde le lien entre les jugements cognitifs des officiels et leurs expériences motrices, visuelles et d'arbitrage. La recherche actuelle est décrite et transférée au champ appliqué des officiels, offrant des implications pratiques. Cette revue montre que pour décrire et comprendre l'expertise des officiels à partir d'un point de vue holistique, l'approche de la cognition incarnée doit être intégrée alors qu'elle a été négligée jusqu'alors dans les travaux sur les officiels des pratiques sportives.

Mots clés : Juges, arbitres, cognition incarnée, expertise

The sports official is one of the essential components of all sport competitions and games. The sports official has to face immense pressure, being able to determine with one single decision about winning or losing, about a gold or silver medal, about financial consequences. To meet with these expectations of making the right decisions, sports officials have to reach a high level of expertise. Experts are characterized by their outstanding skills in their domain and their experience (Ericsson, Charness, \& Feltovich, 2006). To define expertise in 
general, adaptations and changes in perceptual-cognitive skills are one of the most important areas that are taken into account (Williams \& Ford, 2008). Perceptualcognitive skills include for example anticipation, decision making, advance cue utilization, pattern recognition. But how do sports officials reach expertise? How do they optimize their judgments and perform at a high level? What is the role of embodied cognition in officiating? These questions will be addressed by reviewing the history profiles of sports officials that different studies have assessed, summarizing studies that have used different training interventions for sports officials and by outlining studies that have looked at the sources of information they use.

In accordance with expertise research (e.g. Ericsson, et al., 2006), reviewing practice history profiles of expert ${ }^{1}$ sports officials has revealed that an increase in refereeing skills was accompanied by an increase in training volumes (MacMahon, Helsen, Starkes, \& Weston, 2007). Regarding refereeing decisions in soccer, this relation was shown to be quadratic, with increasing refereeing experience (until a peak at 16 years) diminishing the greater leniency of referees toward the home team (Nevill, Balmer, \& Williams, 2002). Superiority in perceptual-cognitive skills has also been shown in expert sports officials in comparison to novices. For instance, expert judges in gymnastics were shown to better anticipate upcoming gymnastics elements, more accurately judge these elements with a superior declarative knowledge base (Ste-Marie, 1999). In addition, expert judges revealed superior error detection (Bard, Fleury, Carriere, \& Halle, 1980) and angle perception skills (Plessner \& Schallies, 2005). Expert soccer referees have been shown to depict superior decision-making skills in tackle situations (MacMahon, et al., 2007) as well as offside decision making (Catteeuw, Gilis, Wagemans, \& Helsen, 2010; Catteeuw, Helsen, Gilis, Van Roie, \& Wagemans, 2009). Especially in ball game sports, decision making is considered one of the main tasks of sports officials, contributing most to refereeing performance with regard to accurately applying the laws of the game (Mascarenhas, Collins, Mortimer, \& Morris, 2005). Since refereeing involves social interaction with the athletes, the decision-making process can best be described by a social information process. According to Plessner and Haar (2006), different sequential steps of information processing lead up to the final observable outcome of the decision. Applied to a referee, first, a situation such as a tackle is perceived. The referee then categorizes the situation (e.g. as a foul) by making use of his memory and organized knowledge. After integrating additional information (e.g. on the severity of the foul), the referee makes his decision, which is followed by his behavioral response. Therefore, superior perceptual-cognitive skills of experts,

\footnotetext{
1 Expert sports officials can be defined as those who either have reached a high amount of accumulated years of officiating experience or have officiated the top competitions within their respective leagues (for a discussion, see MacMahon, et al., 2007).
}

as described above, can be found on each of the sequential steps of information processing, as well as the final outcome, the observable decision.

The above described studies have focused on external factors, which occur outside (external) the body of the sports official and which can influence the quality of officiating. Several other external factors in different sports have been examined (for an overview see MacMahon \& Plessner, 2013; Mascarenhas, O'Hare, \& Plessner, 2006; Ste-Marie, 2003), however, in this chapter we will focus on internal factors. These internal factors are defined as factors which link motor and perceptual processes, hence, experiences that the sports officials have made themselves with their own body. These can be either officiating experience, motor (as athletes) or visual (as spectators) experience. Do these sensory and motor experiences that have shaped their perceptual-cognitive skills as athletes also help them as sports officials to enhance their perceptualcognitive judgments and decisions?

\section{The sports official}

Sports officials can be classified according to the role they play in their sport. Taking into account the amount of interaction with the athletes and the number of athletes/cues being monitored, MacMahon and Plessner (2013) categorize sports officials into three main groups: interactors, reactors and monitors. Whereas soccer, handball, ice hockey referees etc. are characterized as interactors, in charge of enforcing the rules of the game, monitors, e.g., stand for gymnastics or trampoline judges, who observe or assess the quality of performance. A third category are the reactors (e.g. tennis line judges), where perceptual-cognitive skills play a major role.

One aspect that all different types of sport officials have in common is the process of judgment and decision making. Although the two terms are considered to apply to different concepts, they are often tightly linked and together form an important aspect of human cognitive processes. Whereas judgment is defined as "a set of evaluative and inferential processes that people have at their disposal and can draw on in the process of making decisions" (Koehler \& Harvey, 2004, p. XV), decision making itself is characterized by the process of choosing among a set of options. Either deciding on a foul or no foul, if the ball is inside or outside the field or deciding a score between 0 and 10 is just an example of one of the many decisions sports officials have to make over a certain period of time. In order to enhance their decisions, perceptual-cognitive skills have to be trained and supporting strategies have to be integrated. With regard to this classification, task demands of sports officials differ and may also lead to different influencing factors as well as history profiles, since educational structures are not similar. In terms of embodied officiating, this classification might also be reflected in the role bodily experiences 


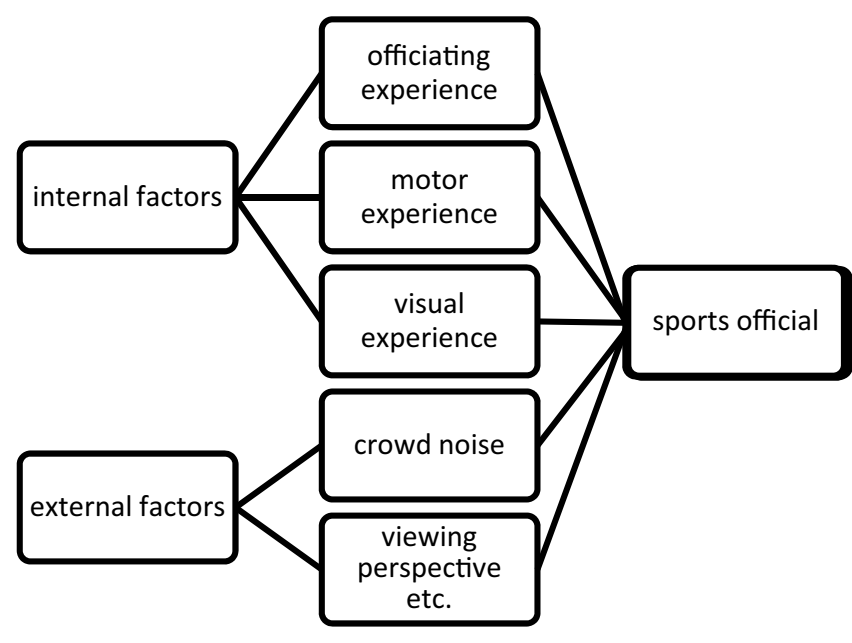

Fig. 1. Factors influencing sports officials.

play for the performance of sports officials. Hence, studies on embodied officiating will be presented that cover a wide range of classes of sports officials.

\section{Internal factors influencing judgment and decision making}

When facing the various demands on the field or at a competition, sports officials are in need of as much information (MacMahon \& Plessner, 2013; Schweizer, Plessner, Kahlert, \& Brand, 2011) and support as possible to integrate the most important cues for their decisions. One way to realize this is to use their own body as a source of information. This perspective will be described in more detail in the following sections.

Over the years of professional officiating as sports officials, but also before that in the role of athletes or spectators in that sport, sport officials have gathered bodily experiences. These so called internal factors (see Pizzera \& Raab, 2012b), which only recently have received attention in research (researchers have mostly focused on external factors) and which in this case are separated from experiences using knowledge of rules from memory (but also take place inside the body, alias internal), can be divided into three areas: officiating experience, motor experience and visual experience (see Fig. 1). In this chapter we will explain these internal factors and discuss recent experiments and their results.

Officiating experience characterizes the experiences sports officials have made during games or competitions in the role of a judge or a referee. The number of years as well as the league level contribute to this experience. Evidence suggests that officiating experience determines the performance quality of sports officials (MacMahon, et al., 2007). Using a video-based tackle assessment task, MacMahon, et al. (2007) showed that a higher amount of officiating experience correlated with better performance quality of Belgian elite soccer referees. Performance quality of sports officials is characterized differently in each sport, although decision or judgment accuracy being the most important aspect. Similarly, officiating skill (characterized by the level of officiating, national vs. international license) of another sample of Belgium top-standard referees was predicted by years of officiating, accumulated practice hours, practice hours per week, and number of matches officiated (Catteeuw, et al., 2009). It is assumed that this officiating experience leads to the development of procedural knowledge, but also strategic knowledge on where to best position oneself to have an optimal viewing perspective (Mascarenhas, et al., 2006).

Motor experience is determined by the bodily experiences sports officials have made as athletes in the sport they now officiate in. This can be either skill level or the amount of practical experience as an athlete in years. If sports officials have been athletes in the sports they officiate in, in the past (applies for most, but not for all), the question arises whether they are more accurate in their decisions when they have felt the movements or physical forces themselves of the actions they have to judge. There are widely held beliefs in the sports arena about this topic. For instance, Heiner Brand, the national coach of the German handball team, voiced an opinion shared by many coaches, managers, athletes, and spectators by stating after a game "This could only be seen by a referee who had himself played in the past!" (RTL television interview, January 17, 2009). Although this statement is based more on intuition, there is research showing that observers use their own motor and kinesthetic experience for visual analysis, indicating that perception is bodydependent (Prinz, 1997). Perceptual judgments can even be enhanced by pure motor training. For instance, in a motor learning study by Casile and Giese (2006) participants who learned novel and unusual arm/leg movements blindfolded, showed improved visual discrimination of the previously learned movements in a visual discrimination task. Similar results were found in a study of bodily influences on the visual perception of intention, where the level of motor experience had an impact on the ability to detect a basketball player's intention (Sebanz \& Shiffrar, 2009). Detecting whether athletes are faking fouls or actually have been fouled as well as judging the intentions of players is one of the numerous aspects of good refereeing in ball game sports. Especially in soccer, there is often tremendous controversy about whether a player is intending to fake a foul or was actually fouled and if the foul was intended or accidental. Consequently, sports officials have to face great demands in detecting these deceptive movements by judging accurately to ensure a fair outcome of the game.

Visual experience refers to the experiences sports officials have made as spectators in the sport they now officiate in. Visual experience in this sense involves watching games/competitions in an objective manner as opposed to being in the role of the sports official with the task of judging or conducting video analysis. In this context, the 
"perceptual experience hypothesis" was introduced which states that perceptual recognition is facilitated by greater visual familiarity, because a better attunement to kinematic information sources is achieved (Jackson, Warren \& Abernathy, 2006; Cañal-Bruland, van der Kamp \& van Kersteren, 2010). Although not conducted with sports officials, Loula, Prasad, Harper, \& Shiffrar (2005) showed in their study that motor as well as visual experience positively influence action perception and, more precisely, the visual analysis of other people's actions. Performance of the participants was best for self and friend trials when having to identify and discriminate point-light depictions of themselves, friends or strangers conducting various actions. As we do not usually have visual experience of our own movements, motor experience is seen as the influencing factor determining the ability to perceive our own actions. Altogether, the study could show that own motor and visual experience of certain movements helped participants to judge better.

One perspective offering a possible explanation of the above described results on motor and visual experiences is that of embodied cognition, which will be described in the next section.

\section{Embodied cognition}

Focusing on the function of cognition for action (see Wilson, 2002, for a discussion of different views), embodied cognition provides a challenging viewpoint in sharp contrast to the classical cognitive theories, where cognition and action are seen as two separate functioning systems independent of each other. The key premise of this "pragmatic turn" understands cognition as subserving action, grounded in sensorimotor coupling (Engel, Maye, Kurthen, \& König, 2013). According to Goldman and de Vignemont (2009, p. 2), a very promising interpretation of embodied cognition is that "mental representations in various bodily formats or codes have an important causal role in cognition". There are several other approaches and theories attempting to define embodied cognition (see Barsalou, 1999, 2008; Niedenthal, Barsalou, Winkielman, Krauth-Gruber, \& Ric, 2005). Considering these different views, I focus on one specifically that can be adapted to the cognitive tasks associated with sports officiating: "Offline-cognition is body based" (see claim 6 of Wilson's Six views on embodied cognition, 2002) and "Offlineeffects of motor action on perception" (Schütz-Bosbach \& Prinz, 2007). This view suggests that mental structures that have originally evolved during action-environment interactions, now run "offline", decoupled from the physical inputs and outputs that were their original purpose, to support cognitive processes such as judgment and decision making. Offline effects therefore describe temporally separated action and perception processes. The idea of a bidirectional link between cognition and action enables the possibility to consider expertise in judges and referees from a totally new perspective. In their book "Mind and Motion: The bidirectional link between thought and action", Raab, Johnson and Heekeren (2009) also focus on this new idea with the aim to achieve a joint understanding of decision making through the multidisciplinary nature of thought and action.

Research in the field of embodied cognition dealing with high performance athletes suggests that, [...] seeing without doing is not enough to achieve excellence (Aglioti, Cesari, Romani, \& Urgesi, 2008, p. 6). In a study with basketball players, basketballs watchers (e.g. coaches and sports journalists) and novices, Aglioti, et al. (2008) showed that predicting other's actions ahead of their realization (which is considered one of the most important aspects to achieve excellence) is related to motor expertise. As basketball players predicted the outcome of a basketball free shot earlier (even when the ball had not yet left the throwers hand) and more accurately than people with no direct motor experience in basketball, they seemed to have extracted relevant information from kinematic cues from the player's body movements, which only own bodily information seems to provide.

One of the underlying mechanisms of embodied cognition can be described by the common coding approach (Prinz, 1997). The main idea is that motor representations of a specific movement (e.g. performing a handstand) are linked with perceptual representations of that movement (e.g. seeing a handstand) in that there is a common code for both action and perception, allowing for the bidirectional transfer between motor training and perceptual judgment. This idea is supported by behavioral (Hecht, Vogt, \& Prinz, 2001) as well as neurophysiological evidence (Calvo-Merino, Glaser, Grèzes, Passingham, \& Haggard, 2005). In a functional magnetic resonance imaging study with expert dancers, Calvo-Merino, et al. (2005) showed increased brain activity in the mirror neuron regions of expert dancers when viewing classical ballet moves they had themselves performed before as opposed to capoeira moves they had not performed. Mirror neurons are neurons that respond both when a particular action is performed and when the same action, performed by another person, is observed (Gallese \& Goldman, 1998). On a behavioral level, this was also shown in a study by Jackson, et al. (2006) on rugby players of different skilllevels. Experts with a high amount of visual and/or motor experience were significantly better in the detection of deceptive actions that novices. Therefore, skill-level difference in sensitivity to advance visual information also extends to deceptive information. Following this idea of visuomotor couplings, the question arises if bodily experiences can develop and improve perceptual-cognitive skills such as judgment and decision making of sports officials in such a way that a high level of expertise is reached.

\section{Embodied cognition in judges and referees}

Do sport officials use their former motor skills to enhance their current perceptual skills through the 
action-perception transfer? If judges are influenced by such bodily experience, using this coding system (see common coding approach by Prinz, 1997) as a platform to form perceptual judgments, then their judgments should be enhanced by motor training.

To get an idea of how expertise and bodily experiences relate in different classes (see classification of sports officials according to MacMahon \& Plessner, 2013) of elite sports officials of different sports in Germany, an exploratory study was conducted with 370 judges and referees from soccer, handball, ice hockey and trampoline (Pizzera \& Raab, 2012b). Data of a questionnaire assessing visuomotor experience, officiating experience and performance measures of these different sports officials were correlated and analyzed via regression analysis. The results showed that cognitive judgments are tuned by motor and visual experience to different degrees in the analyzed sports. Depending on the sport, officiating, motor and visual experience were differently important factors for the performance of sport officials. For instance, officiating experience best predicted the performance of handball and ice hockey referees as well as trampoline judges. Consequently, in these sports, an early specialization as sport officials should be considered, to ensure many years of practical experience (officiating experience) at an early age. For soccer referees, this study revealed a nonlinear relation between officiating performance and officiating experience, in that a minimum of 10 years should be reached to enhance officiating performance. This was in accordance with the results of Nevill, et al. (2002) on soccer referees, where referees' decisions and officiating experience showed a quadratic relation. Furthermore, not only the number of officiating years, but also a high frequency of judging competitions/refereeing games showed to be important to increase practical experience. However, with regard to refereeing performance in soccer, visual experience was found to be even more important, as indicated by a higher amount of explained variance in the regression analysis.

Although the data showed that an early specialization as a sports official is important in handball, trampoline and ice hockey, motor experience (in years) also significantly predicted ice hockey referee and trampoline judging performance. Therefore, learning how to play ice hockey and experiencing the characteristics of an ice hockey game as an athlete, or feeling the biomechanical characteristics and physical forces as a trampolinist may be useful indications for good officiating performance. Visual experience was found to be an important factor in soccer and handball. Showing a cubic relation, officiating performance increased with more years of visual experience until about 10 years and starting from 25 years. Visual experience between 10 and 25 years did not result in increased officiating performance. Again, visual experience in this sense means the experiences sports officials have made as spectators, e.g. either in the stadium or in front of the TV.
This exploratory study revealed that, indeed, elite sports officials collected quite an amount of visuomotor and officiating experiences and that these experiences were related to the sports officials' officiating performances. However, officiating performance measures were based on written exams and evaluation forms of referee observers and coaches (with less objectivity as a limiting factor) and retrospectively correlated to the different experiences of the sports officials. In an experimental study in pole vaulting (Pizzera \& Lobinger, 2014), participants were asked to judge pole vaulting jumps on rule violations. Participants were divided into groups reflecting their different experiences: pole-vaulting judges (officiating experience), pole vaulting athletes (motor experience) and pole-vaulting spectators (visual experience). In an online-video test they were asked to judge whether pole vaulting athletes stabilized and/or pushed back the bar while crossing it. The results revealed that judges and athletes were similarly accurate and confident in their judgments, while spectators showed less accuracy and confidence. However, officiating and motor experience were not easily distinguishable, since some pole-vaulting judges had also collected motor experiences as athletes before. Still, athletes showed similar judgment accuracy as judges, in a judging specific task that is not familiar to them. The confounding limitations of the pole-vaulting study were quite nicely overcome in an experimental study with gymnastic judges by Pizzera (2012). Judges were asked to judge a specific element with regard to its quality, taking into account the official judgment criteria of the International Gymnastics Federation (FIG, 2009). The optimal reference score for each video clip was determined through detailed video analyses and expert judges' ratings using video replays and slow motion. Higher judgment accuracy indicated less deviation from the reference score. The results showed that judges who could perform the skill themselves were significantly more accurate in their judgments than judges who could not perform the skill. With such results the question arises to which extent such motor experiences contribute to judging performance in comparison to visual or judging experience. A regression analysis was conducted resulting in a regression model in which specific motor experience (judges who could perform the skill) significantly predicted the judging scores with $26 \%$ variance explained. Interestingly, the regression strength was not improved by adding general motor experience, visual or judging experience.

The effect of this very specific motor effect leads to an interesting question: if such motor experience could even be trained, would this result in better perceptual judgments of sports officials? This idea was put forward in a study with football players (Pizzera \& Raab, 2012a). Expert football players were chosen to investigate pure motor or visual experience effects, without additional knowledge as a referee. Over the course of six weeks, participants were trained to fake fouls in different categories. They were instructed to conduct 1-on-1 situations (offensive against defensive player), with the offensive player 
being asked to simulate having been fouled, as soon as the two players made body contact. These situations represent typical scenarios during football games, leading to ambiguous foul situations which are difficult to judge as a referee. The hypothesis based on the embodied cognition approach was that participants, who have experienced the situations themselves, would be better able to put themselves into the players' shoes and therefore judge such deceptions more accurately. A second group watched the training, collecting visual experience, while a third group served as a control group. All participants were tested concerning their decision-making performance, by having them judge video clips showing ambiguous foul situations. They were instructed to decide on no foul, foul, foul with a yellow card or foul with a red card. The results revealed no immediate effects of the training; however, the motor group showed to be more accurate in the long run, as reflected in the retention test. In addition to this finding, general visual experience was shown to enhance deception detection for all three groups.

A study by Renden, Kerstens, Oudejans, and CañalBruland (2012) also addressed the contributing factors that characterize the ability to judge deceptive actions. Participants were asked to watch football video clips, showing potential tackle situations and judge whether falls were caused by fouls or dives. An expert panel watched the selected video clips, including replays from different angles and judged if the video clips showed a foul or a dive. Similar to the pole vaulting study, groups were compared, representing their experiences (football referees, skilled football players, wheelchair-bounded football fans, novices). The inclusion of wheelchair-bounded football fans nicely addressed the usually critical limitations of such studies, in that motor and visual experiences are often confounded. In accordance with other studies on embodied officiating, referees and players showed the highest judging accuracy, while fans and novices were less accurate. Interestingly, mere visual experience did not enhance judgment accuracy, as fans were worse than players and not better than novices.

Most of the sports officials usually start off as athletes and according to the above described studies, this seems to link with the sports officials' performances more or less, depending on the type of sport or the classification of the sports official. Such role-transitions, in which players become referees, have specifically been examined, explaining performance in decision-making tasks better than rolebased differences (MacMahon, Starkes, \& Deakin, 2009).

Coming back to the social information processing framework, the above described studies mostly examined the outcome of this process, hence, the observable decision. What remains unknown, are the underlying processes that link the motor and perceptual processes of sports officials. Are the different steps of the information process differently affected by their own body? Do sports officials "perceive with other eyes" or integrate information differently if they have formerly been active in the sport as athletes? Or is there no difference in the different steps, but rather the whole process is or is not affected depending on the type of sport or class of sports officials, as suggested by studies so far?

\section{Practical implications}

The above described results indicate that officiating, as well as motor and visual experiences contribute to the development of sports officials and their performance. But how can these findings be transferred to the applied field? In general, sport associations could consider different approaches to the selection, education, advanced training and evaluation of their sports officials. New restrictions in the selection of future sports officials could be conducted. In equestrian dressage in Germany, e.g., prospective judges are currently already required to possess medals (won as athletes in the same discipline) on a certain level to be able to become a judge. Similar requirements are to be met in judo in France. Therefore, to be able to reach a certain level of sports official expertise, a certain level of motor and visual expertise is to be acquired, according to these associations. However, similar to the study by Pizzera (2012), relative weightings of experiences need to be conducted to examine if such motor experiences outweigh officiating experience and consequently to evaluate the usefulness of such practices in the respective sport.

For the education and advanced training, sport associations could even enhance officiating, motor and visual experience during their sport official education program leading to even higher expertise. Decision-making training with the use of video-training tools has been shown to increase decision-making accuracy and should therefore be considered in terms of visual training leading to officiating experience (Schweizer, et al., 2011; Put, Wagemans, Jaspers, \& Helsen, 2013). With regard to visual experience, referees in soccer, e.g. could be required to watch live competitions or games, which could be signed regularly by the respective event officials in order to give credit for visual experience. Taking into account the study of Pizzera \& Raab (2012b), specific thresholds for visual experience in years could be determined. This visual experience could then be of use to enhance judgment accuracy in ambiguous situations in the sense of detecting the real intention of the tackled player, which has also been found to be the reason for variance of judgment (Morris \& Lewis, 2010). Regularly, soccer referees face the challenge to decide whether a tackled player deceptively exaggerated the effect of a tackle or was actually fouled. In this sense, visual experience may help to develop effective gaze strategies to take up the relevant cues necessary to make accurate judgments. However, with regard to the study by Renden, et al. (2012), visual experience should always be combined with motor experience. For other sports such as technical sports, the educational program of judges could contain practical training, teaching the basics of the sport 
in the role of an athlete. The aim of such a motor training is to point out and perceive the kinesthetic characteristics of different movements and understand from an ego-perspective how different body components and limbs work together. Since this is not always possible, especially in the case of older adults, judging panels could be put together which include at least one former elite athlete. Therefore, selecting retired high-performance athletes for the job as a judge might be a possibility. These judges might have better abilities to put themselves into the body of the athletes they are observing and interpret an athlete's intentions correctly and consequently spot deceptions accurately (e.g. gymnasts trying to cover up errors in order to get fewer deductions).

Altogether, former as well as current visuomotor experiences contribute to the enhancement of judgment and decision-making accuracy in games and competitions. The education systems of the different sport associations could use this information to form their sports official experts by changing the requirements to enter the education program, but also by training ambiguous situations in balls games, for instance.

\section{Conclusion}

At the beginning of this chapter we asked three questions: How do sport officials reach expertise? How do they optimize their judgments and perform on a high level? What is the role of embodied cognition in officiating?

In conclusion, experts in officiating sport events share a wide variety of expertise across different domains. Following studies conducted with sport athletes on the required amount of deliberate practice to attain expert performance (Ericsson, et al., 2006), officiating experience should also cover a minimum of about 10 years.

Besides officiating experience developing alongside the career, training specifically designed for a sport official's task has been shown to help developing expertise by increasing experience. This has been applied to offside decision-making training (Put, et al., 2013) and decision-making training of tackle situations for soccer referees (Schweizer, et al., 2011) as well as rugby referees (Mascarenhas, et al., 2005).

In addition, embodied officiating, a new approach to sports officiating research, provides promising results in that out of the perspective of embodied cognition, visuomotor experiences may contribute to sports official expertise. Motor experience, either in the sense of skill level or in the sense of amount in years shows to be an influencing factor regarding sports officials' performance and, therefore, expertise. Depending on the sport, judges and referees show better performance quality with a higher amount of motor experience. Visual experience, subclassified into frequency (how often per week, month) and amount (in years), additionally leads to better performance quality. However, this is highly dependent on the type of sport. Whereas for some sports these experiences may not be relevant (physically training the dive did not improve accurate perception, Pizzera \& Raab, 2012) or maybe even hinder sports officiating (e.g. thinking too much out of the perspective of an athlete), other sports officials seem to benefit from their bodily experiences by using them as a source of information to implement their judgments and decisions on a high level.

The link from judgment and decision making of sports officials to the field of embodied cognition offers a wide variety of practical implications, which especially the education programs for sports officials should take into account in the sense of selection, education, advanced training and evaluation of sports officials. When addressing the goal of enhancing perceptual judgments, the possibility should be considered that sports officials use their own body to support perception and cognition and, therefore, perceptual judgments. Further research is needed in this new field by experimentally testing the influence of visuomotor experience on the performance quality of sport officials. Results found in the field of embodied cognition with athletes or movements in general should be transferred to the applied field of judgment and decision making of sports officials. Consequences for researchers following the ideas of classical theories, where cognition and action were seen as independent from each other, are that they should reconsider their theories and take into account the bidirectional link between cognition and action. Judges and referees could be tested in their judgment quality or decision-making skills, after having learned or observed movements or actions they have to judge on a regular basis.

On a long term basis, expertise of sports officials could then be enhanced by additional sources of information in using the ideas of the bidirectional link between cognition and action. Bodily experiences should help judges and referees to meet the high challenges of making the optimal judgments of high speed movements as conducted, for instance, in gymnastics or trampoline and making the optimal decisions in ambiguous ball game situations to guarantee a fair outcome of games and competitions.

\section{Bibliography}

Aglioti, S.M., Cesari, P., Romani, M., \& Urgesi, C. (2008). Action anticipation and motor resonance in elite basketball players. Nature Neuroscience, 11, 1109-1116.

Bard, C., Fleury, M., Carriere, L., \& Halle, M. (1980). Analysis of gymnastics judges' visual search. Research Quarterly for Exercise and Sport, 51 (2), 267-273.

Barsalou, L.W. (1999). Perceptual symbol systems. Behavioral and Brain Sciences, 22, 577-660.

Barsalou, L.W. (2008). Grounded cognition. Annual Review of Psychology, 59, 617-645.

Calvo-Merino, B., Glaser, D.E., Grèzes, J., Passingham, R.E., \& Haggard, P. (2005). Action observation and acquired 
motor skills: An fMRI study with expert dancers. Cerebral Cortex, 15 (8), 1243-1249.

Cañal-Bruland, R., van der Kamp, J., \& van Kersteren, J. (2010). An examination of motor and perceptual contributions to the recognition of deception from others' actions. Human Movement Science, 29, 94-102.

Casile, A., \& Giese, M.A. (2006). Nonvisual motor training influences biological motion perception. Current Biology, 16, 69-74.

Catteeuw, P., Gilis, B., Wagemans, J., \& Helsen, W.F. (2010). Perceptual-cognitive skills in offside decision making: Expertise and training effects. Journal of Sport and Exercise Psychology, 32, 828-844.

Catteeuw, P., Helsen, W., Gilis, B., \& Wagemans, J. (2009). Decision-making skills, role specificity, and deliberate practice in association football refereeing. Journal of Sports Sciences, 27 (11), 1125-1136.

Engel, A. K., Maye, A., Kurthen, M., \& König, P. (2013). Where's the action? The pragmatic turn in cognitive science. Trends in Cognitive Sciences, 17 (5), 202-209.

Ericsson, K.A., Charness, N., \& Feltovich, P.J. (2006). The Cambridge handbook of expertise and expert performance. Cambridge: Cambridge University Press.

FIG - Fédération Internationale de Gymnastique (2009). Code of Points - Women's Artistic Gymnastics. Moutier, Switzerland.

Gallese, V., \& Goldman, A. (1998). Mirror neurons and the simulation theory of mind-reading. Trends in Cognitive Sciences, 2 (12), 493-501.

Goldman, A., \& de Vignemont, F. (2009). Is social cognition embodied? Trends in Cognitive Sciences, 13 (4), 154-159.

Hecht, H., Vogt, S., \& Prinz, W. (2001). Motor learning enhances perceptual judgment: a case for action-perception transfer. Psychological Research, 65, 3-14.

Jackson, R.C., Warren, S., \& Abernathy, B. (2006). Anticipation skill and susceptibility to deceptive movement. Acta Psychologica, 123, 355-371.

Koehler, D.J., \& Harvey, N. (Eds.). (2004). Blackwell handbook of judgment and decision making (1st ed.). Malden, MA: Blackwell.

Loula, F., Prasad, S., Harper, K., \& Shiffrar, M. (2005). Recognizing people from their movement. Journal of Experimental Psychology: Human Perception and Performance, 31 (1), 210-220.

MacMahon, C., Helsen, W.F., Starkes, J.L., \& Weston, M. (2007). Decision-making skills and deliberate practice in elite association football referees. Journal of Sports Sciences, 25 (1), 65-78.

MacMahon, C., \& Plessner, H. (2013). The sport official in research and practice In C. MacMahon, D. Farrow \& J. Baker (Eds.), Developing sport expertise - Researchers and coaches put theory into practice (pp. 71-95). London: Routledge.
MacMahon, C., Starkes, J.L., \& Deakin, J. (2009). Differences in processing of game information in basketball players, coaches and referees. International Journal of Sport Psychology, 40, 403-423.

Mascarenhas, D.R.D., Collins, D., Mortimer, P.W., \& Morris, B. (2005). Training accurate and coherent decision making in rugby union referees. The Sport Psychologist, 19, 131147.

Mascarenhas, D., O'Hare, D., \& Plessner, H. (2006). The psychological and performance demands of association football refereeing. International Journal of Sport Psychology, 37, 99-120.

Morris, P.H., \& Lewis, D. (2010). Tackling diving: The perception of deceptive intentions in association football (soccer). Journal of Nonverbal Behavior, 34, 1-13.

Nevill, A.M., Balmer, N.J., \& Williams, A.M. (2002). The influence of crowd noise and experience upon refereeing decisions in football. Psychology of Sport and Exercise, 3, 261-272.

Niedenthal, P.M., Barsalou, L.W., Winkielman, P., KrauthGruber, S., \& Ric, F. (2005). Embodiment in attitudes, social perception, emotion. Personality and Social Psychology Review, 9 (3), 184-211.

Pizzera, A. (2012). Gymnastic judges benefit from their own motor experience as gymnasts. Research Quarterly for Exercise and Sport, 83 (4), 603-607.

Pizzera, A., \& Lobinger, B.H. (2014). Influence of visuomotor experience on judging quality and judging confidence of judges in pole vaulting. Zeitschrift für Sportpsychologie German Journal of Sport Psychology, 21 (3), 95-103.

Pizzera, A., \& Raab, M. (2012a). Does motor or visual experience enhance the detection of deceptive movements in football? International Journal of Sports Science $\&$ Coaching, 7 (2), 269-283.

Pizzera, A., \& Raab, M. (2012b). Perceptual judgments of sports officials are influenced by their motor and visual experience. Journal of Applied Sport Psychology, 24 (1), 59-72.

Plessner, H., \& Haar, T. (2006). Sports performance judgments from a social cognitive perspective. Psychology of Sport and Exercise, 7, 555-575.

Plessner, H., \& Schallies, E. (2005). Judging the cross on rings: A matter of achieving shape constancy. Applied Cognitive Psychology, 19, 1145-1156.

Prinz, W. (1997). Perception and action planning. European Journal of Cognitve Psychology, 9 (2), 129-154.

Put, K., Wagemans, J., Jaspers, A., \& Helsen, W.F. (2013). Web-based training improves on-field offside decisionmaking performance. Psychology of Sport and Exercise, $577-585$.

Raab, M., Johnson, J.G., \& Heekeren, H.R. (Eds.). (2009). Mind and motion: The bidirectional link between thought and action. New York: Elsevier. 
Renden, P.G., Kerstens, S., Oudejans, R., \& Cañal-Bruland, R. (2012). Foul or dive? Motor contributions to juding ambiguous foul situations in football. European Journal of Sport Science, 14 (Suppl. 1), S221-S227.

Schütz-Bosbach, S., \& Prinz, W. (2007). Perceptual resonance: action-induced modulation of perception. TRENDS in Cognitive Science, 11 (8), 349-355.

Schweizer, G., Plessner, H., Kahlert, D., \& Brand, R. (2011). A video-based training method for improving soccer referees' decision-making skills. Journal of Applied Sport Psychology, 23 (4), 429-442.

Sebanz, N., \& Shiffrar, M. (2009). Detecting deception in a bluffing body: The role of expertise. Psychonomic Bulletin Es Review, 16 (1), 170-175.
Ste-Marie, D.M. (1999). Expert-novice differences in gymnastic judging: An information-processing perspective. Applied Cognitive Psychology, 13, 269-281.

Ste-Marie, D.M. (2003). Expertise in judges and referees. In J.L. Starkes \& K.A. Ericsson (Eds.), Expert Performance in Sports (pp. 171-189): Human Kinetics.

Williams, A.M., \& Ford, P.R. (2008). Expertise and expert performance in sport. International Review of Sport and Exercise Psychology, 1 (1), 4-18.

Wilson, M. (2002). Six views of embodied cognition. Psychonomic Bulletin and Review, 9 (4), 625-636. 